\title{
Creating Transformative Service-Learning Partnerships as a Force for Change in Higher Education
}

\author{
Stephanie Bingham
}

Barry University, USA

\section{Recommended Citation}

Bingham, S. (2021). Creating transformative service-learning partnerships as a force for change in higher education [Review of the book Service learning to advance access and success: Bridging institutional and community capacity, ed. by T. T. York, A. S. Tinkler, \& B. E. Tinkler]. International Journal of Research on Service-Learning and Community Engagement, 9(1), Article 12. https://doi.org/10.37333/001c.31320 


\section{Creating Transformative Service- Learning Partnerships as a Force for Change in Higher Education}

Service-Learning to Advance Access and Success: Bridging Institutional and Community Capacity, edited by Travis $\mathrm{T}$. York, Alan S. Tinkler, and Barri E. Tinkler. Information Age Press, Charlotte, NC, USA. 2018. ISBN-13: 978-1-64113-474-3 (Paperback). 346 pp.

Reviewed by Stephanie Bingham

Service-Learning to Advance Access and Success: Bridging Institutional and Community Capacity addresses how partnerships between institutions and communities can be leveraged to build community capacity as well as how institutions might build their own capacity to effect change for the good of society. Case studies detailed in the book explore the relationship between servicelearning pedagogy and student access and success. Together, the chapters serve as a call to action to make more collaborative and sustainable efforts toward meaningful integration of service-learning into the curriculum and campus culture while providing practical advice on how to do so successfully.

\section{Creando alianzas transformadoras de aprendizaje en servicio como Fuerza para el Cambio en la educación superior}

Cuestiones para reflexionar: estudios sobre aprendizaje-servicio en Asia, editado por Robert Shumer, Carol Ma Hok Ka, y Constance Chan Wing Yee. Information Age Press, Charlotte, NC, USA. 2021. ISBN-13: 978-1-64802-509-9 (Libro en rústica). 142 páginas.

Reseñado por Stephanie Bingham

\section{Service-Learning to Advance Access and} Success: Bridging Institutional and Community Capacity (Aprendizaje en servicio para fomentar el acceso y el éxito: uniendo la capacidad comunitaria a la institucional) aborda cómo las alianzas entre instituciones y comunidades pueden ser aprovechadas para afianzar las capacidades comunitarias, así como la manera en que las instituciones podrían desarrollar sus propias capacidades para efectuar un cambio beneficioso para la sociedad. Los estudios de casos detallados en este libro exploran la relación de la pedagogía del aprendizaje en servicio con el acceso y el éxito de los estudiantes. En su conjunto, los capítulos sirven como una llamada a la acción para realizar más esfuerzos colaborativos y sostenibles que lleven a la integración significativa del aprendizaje en servicio en los planes de estudio y en la cultura del campus, al mismo tiempo que proporcionan consejos prácticos acerca de cómo poderlos aplicar con éxito.

Palabras clave: acceso, desarrollo de capacidades, aprendizaje basado en la comunidad, aprendizaje en servicio, éxito de los

estudiantes
Keywords: access, capacity building, communitybased learning, service-learning, student success

Editors' Note: English-to-Spanish translation by Yamilet Hernandez

Department of English and Foreign Languages

Barry University, USA 
Service-Learning to Advance Access and Success: Bridging Institutional and Community Capacity addresses how partnerships between institutions and communities can be leveraged to build community capacity as well as how institutions might build their own capacity to effect change for the good of society. This volume in the Advances in Service-Learning Research series highlights the diverse and innovative ways in which institutions can address potential barriers to effective implementation of service-learning. The 12-chapter volume - which is supplemented by a Foreword, Introduction, and Epilogue - is artfully organized into three sections, each a treasure trove of resources for the new and seasoned service-learning practitioner alike.

Editors Travis T. York, Alan S. Tinkler, and Barri E. Tinkler help readers tease out the fundamental issues surrounding three important themes: a framework for capacity building through assessment, institutional strengthening through university-community collaborations, and reimagining what student success and teacher training can look like in a service-learning context. To that end, empirical evidence and insights are offered through case studies that illuminate the considerations involved in the implementation of successful service-learning strategies.

Penned by York, the Introduction sets the stage for delving into critical questions that lie at the heart of service-learning research such as what the best practices are for creating and sustaining effective servicelearning partnerships that address systemic inequalities. The Introduction also provides an overview of the major themes of the book, emphasizing how service-learning can be leveraged to produce sustainable and meaningful gains for all stakeholders through effective capacity building.

This volume's contributing authors are primarily faculty from diverse institutions of higher education, but they also include an undergraduate research assistant, graduate and post-doctoral researchers as well as university administrators and community organizers. They share case studies from an array of academic disciplines and community-based learning approaches, adding to the richness of this volume.

Section I, "Collaboration to Build Community Capacity," focuses on the various approaches to achieving meaningful gains in the implementation of service-learning. Chapter 1, authored by Rebecca Pearson and Naomi Jeffery Petersen, provides insight into effective assessment practices, an oftenneglected aspect of service-learning, due in part to the difficulty in gathering quantitative data. Particular attention is paid to assessment through various instruments, which aims to determine whether, and to what extent, students and community partners benefit from a partnership. In Chapter 2, Chloe Latham Sikes, Tracie Lowe, and Suchitra V. Gururaj place emphasis on best practices and innovative approaches to building community capacity through effective partnership. They conclude that place-based approaches are poised to make the significant impact in this regard. In the final chapter of this section, Dennis McCunney and Guiseppe Getto make the case for utilization of participatory action research to build capacity within nonprofits, specifically their capacity to communicate effectively with key audiences, including volunteers, donors, funders, and prospective clients.

In Section II, "Institutional Capacity to Achieve Change," the concept of engaged department initiatives (EDI), those that encourage cross-disciplinary alliances, is introduced as a vehicle for creating a culture of sustainable and collaborative community engagement. According to Williams Howe et al. (2010, as cited in Lake et al.; see Chapter 4 of this volume), engaged departments may be defined as academic units that "not only share 'a common commitment to community engagement and public scholarship, but also support each other in carrying out the best practices of these commitments" (p. 78).

In this section, the authors explore the question of whether EDIs are, in fact, an effective driving force behind institutional change. As part of this investigation, two major questions are addressed: which conditions are optimal for leveraging the capacity of EDIs to promote institutional change, and what resources are needed to bring about these university-wide changes. As stated by Coauthors Danielle Lake, Karyn E. Rabourn, Nicholas O. Scobey, and Gloria Mileva in Chapter 4, EDIs have the capacity to facilitate systemic shifts in institutional attitudes toward the importance of community-based learning and research. They acknowledge that resources and infrastructure - particularly faculty with prior experience with community-based education; the careful building and maintenance of community partnerships; and support from upper administration for community-engaged teaching, learning, and scholarship - are an essential component of successful EDIs. In Chapter 5, Julianne Gassmann, Emily J. Shields, Katie Kleinhesselink, 
and Elaine K. Ikeda discuss the effects of targeted faculty and community partner training on the cocreation process and how this approach can inform the establishment of authentic partnerships because of a deeper, shared understanding of the goals and scope of service-learning. Chapter 6 closes out the section with Connie Snyder Mick, Annie Cahill Kelly, and Sam Centellas addressing the so-called "trifecta of stakeholder development: courses that advance the goals of students, faculty, and communities all at once" (p. 123) by taking intentional steps to model principles of the Carnegie Classification's definition of community engagement (see Commission on Public Purpose in Higher Education, n.d.).

Section III is titled "Advancing Student Access and Success." The six chapters in this section provide insights into reimagining what student engagement and success can be in the context of service-learning. In Chapter 7, R. Tyler Derreth explores the benefits of critical service-learning, in which coinvestigators learn from, as well as with, one another. Chapter 8, coauthored by Patricia M. Ryan, Shirley M. Matteson, and Valerie O. Paton, explores the topic of graduate students as a largely untapped resource for engaged scholarship. Through their introduction to engaged scholarship and exposure to service-learning pedagogy, graduate students become equipped to utilize service-learning approaches in their own curriculum. The benefits of this approach cannot be overstated, from the positive impacts on research quality and teaching skills to overall community engagement know-how.

Chapter 9 examines the implementation of cocurricular service-learning and potential impacts on student growth and commitment to social justice. Chapter coauthors Laura Martin, Albert Nylander, and Lakyre'a Janae Owens note that cocurricular experiential learning opportunities can lead to "personal and systemic transformation" (p. 224).

In Chapter 10, Michael Kopish details a multiple-case study in Appalachian Ohio focused on teacher candidate preparation and the application of third-space principles that place value on dialectical relationships among all stakeholders. Adoption of these principles is credited with enhancing teacher training beyond acquisition of knowledge and skills - with development of competencies related to democratic citizenship. In Chapter 11, Gary Harfitt and Jessie Mei Ling Chow describe the inclusion of service-learning initiatives as a required component of teacher training in a global setting with nongovernmental organizations (NGOs). The authors note that NGO partnerships provide a framework for bridging theory and practice as well as for developing important qualities: "collaboration, learnercenteredness, and a renewed passion for teaching, awareness of others, lifelong learning, risk-taking, and responsibility" (p. 305). Yasemin Kırkgöz closes Section III with another multiple-case study on servicelearning as an effective component of teacher candidate training. The primary implication from Section III is that intentional and thoughtfully designed service-learning will allow participants to leave the experience empowered, having a greater sense of purpose, feeling better connected to their communities, and appreciative of the impact of transformational service.

Coeditor Alan Tinkler closes the volume, bringing the reader full circle by reiterating the close alignment of the cases and their findings to that the seminal ideas of service-learning forefathers John Dewey and Paolo Freire. Alan Tinkler reinforces the positive and transformative impact of service-learning as an instrument for social change and expresses hope for the future of service-learning and its capacity to tackle complex social issues such as poverty and climate change.

Service-Learning to Advance Access and Success offers case studies that explore the relationship between service-learning pedagogy and student access and success. This volume effectively outlines best practices for meaningful civic engagement and service-learning outcomes in an accessible manner. It provides a balanced, honest view of the preparation that is needed and identifies potential challenges as well as potential rewards of well-designed and executed service-learning initiatives. Refreshingly, the authors acknowledge barriers to effective and sustainable service-learning implementation while simultaneously offering workable solutions that address many of these challenges.

Together, the chapters serve as a call to action to make more collaborative and sustainable efforts toward meaningful integration of service-learning into the curriculum and campus culture while providing practical advice on how to do so successfully. A major strength of this volume is that there is something for everyone regardless of their level of experience with service-learning, the specific service-learning methodology they utilize, or the type of institution. Further, the diverse accounts of innovative 
programming give practitioners a license to be creative and adaptable when developing service-learning initiatives to ensure that all stakeholders derive maximum benefit from the partnership. As reiterated throughout, this is accomplished through (1) assessing, acknowledging, and leveraging each stakeholder's strengths and (2) keeping lines of communication open for continuous feedback and responsiveness to the feedback. By implementing these core principles, stronger, more effective university-community partnerships can be established. Such partnerships can be truly transformative, functioning as a force for positive change in higher education.

\title{
Reference
}

Commission on Public Purpose in Higher Education. (n.d.). Defining community engagement. Retrieved December 20, 2021, from https://public-purpose.org/initiatives/carnegie-electiveclassifications/community-engagement-classification-u-s/

\author{
About the Author \\ Stephanie Bingham, Ph.D., is a professor of biology and a member of the Faculty Learning Community \\ for Engaged Scholarship at Barry University. \\ Correspondence concerning this article should be addressed to Stephanie Bingham at \\ sbingham@barry.edu.
}

